\title{
Surface Wettability and Morphology Implications on Interfacial Interactions of Chitosan with Certain Biological Media
}

\author{
ANDREEA IRINA BARZIC ${ }^{*}$, RALUCA MARINICA ALBU ${ }^{1}$, IULIANA STOICA ${ }^{2}$, \\ BOGDAN OPRISAN ${ }^{3}$ \\ 1 "Petru Poni" Institute of Macromolecular Chemistry, Department of Physical Chemistry of Polymers, 41A Grigore Ghica \\ Voda Alley, 700487, Iasi, Romania \\ 2 "Petru Poni" Institute of Macromolecular Chemistry, Department of Polymeric Materials Physics, 41A Grig ore Ghica Voda \\ Alley, 700487, Iasi, Romania \\ 3 "Grigore T. Popa" University of Medicine and Pharmacy, Faculty of Medicine, Discipline Biophysics and Medical Physics, \\ 16 University Str., 700115, Iasi, Romania
}

\begin{abstract}
Plastic materials based on biopolymers are of great importance in biomedical field. In this article, chitosan was investigated to elucidate the impact of the surface topography parameters and wettability on its interaction ability with certain biological molecules. The physicochemical properties of chitosan in acetic acid environment are analyzed by molecular modeling to predict some of the films properties. Morphology images show a hill-valley-structured surface of nanoscale level, with low surface bearing properties and valley fluid retention. Wetting features were determined for evaluation of the balance between the adhesion and cohesion forces acting at the biointerface. wetting or dewetting behavior of chitosan with several biological media.
\end{abstract}

Keywords: biopolymer, morphology, molecular modeling, biointerface

\section{Introduction}

In the past decades, research trends in the area of plastic materials were progressively directed towards biopolymers owing to their less harmful effects on the environment and living organisms [1,2]. Among natural polymers, chitosan is widely studied since it is a nontoxic and eco-friendly material $[3,4]$. This cationic polysaccharide is mainly prepared by partial deacetylation of chitin, which in turn is extracted from crustacean shells [5], butterfly wings [6] or beetles [7]. The quality and implicitly the properties of chitosan are influenced by the source of chitin and its separation procedure but also by the degree of deacetylation of chitin [8]. Chitosan has outstanding biological characteristics, like being biodegradable, biocompatible, mucoadhesive, combined with antioxidant, antitumor and antimicrobial properties. These features make this biopolymer very attractive for various applications in biomedicine. However, in spite of its good physicochemical characteristics and unique biological properties, chitosan is not soluble in water above $p \mathrm{H} 7$ due to its crystallinity. This aspect is narrowing the applicability of this biopolymer in living systems. Thus, it is rather useful as hemostats, wound healing gels, scaffolds or antimicrobial material for fabrication of medical instrumentation / devices or external therapeutic agents [9].

Surface wettability and morphology of chitosan is extremely important in biological applications. Literature reports [10-15] on surface energy of this polymer present some puzzling data meaning that the expected prevalent surface polarity typical for polysaccharides is not observed for chitosan. The main structural difference between this polymer, cellulose and starch resides in substitution of an $\mathrm{OH}$ group in each saccharide unit of cellulose with an $\mathrm{NH}_{2}$ in chitosan and by the presence of branched segments in starch. Cunha et al [16] explains this dramatic difference in wetting behavior of pelleted powder by revealing that even the most pure commercial chitosan samples contain nonpolar impurities (absent in the monomeric counterpart) that lower the polar component of surface tension. Also, it was showed that surface roughness of the chitosan pellets had no significant influence on the surface wettability.

*email: irina_cosutchi@yahoo.com 
Other investigations [15, 17-20] on morphology of chitosan evidenced a relatively smooth surface with variable porosity as a function of the preparation conditions. All discussed surface features are influencing the interaction of chitosan with biological media, which is of paramount importance in applications.

In this context, this work aims to perform a complex analysis of chitosan starting from the conformational properties in the selected solvent for processing the solid films, continued with a detailed morphological examination using parameters that were not discussed by now for this structure. In addition, all these data are corroborated with the interactions of chitosan with blood, cells, and microorganisms to understand for which biomedical application the studied biopolymer is more suitable.

\section{Materials and methods}

Chitosan sample having a low molecular weight and a degree of deacetylation ranging between 7585\%, was used as received (Sigma Aldrich). The chitosan solutions in acetic acid (HAc) were filtered, casted on Petri dish and then dried for several days to obtain the solid films.

Molecular modeling was done with Hyperchem 8.0 demo version software. The program settings are: root mean square (RMS) gradient of $0.001 \mathrm{k} \mathrm{cal} / \hat{\AA} \cdot \mathrm{mol}$, Polak-Ribiere algorithm, BIO+(CHARM) by molecular mechanics force field, and PM3 semi-empirical theory.

Atomic force microscopy (AFM) measurements were performed on a Solver Pro-M Scanning Probe Microscope (NT-MDT, Russia), in air, at $23^{\circ} \mathrm{C}$, using a NSG10 cantilever with a resonant frequency of $245 \mathrm{kHz}$. The AFM topographical images were acquired using Nova software from NT-MDT in tapping mode, on different scan areas, for example being chosen an area of $20 \times 20 \mu \mathrm{m}^{2}$. The tridimensional parameters were calculated from the height histogram and Abbott-Firestone curve using Image Analysis 3.5.0.19892 software.

Surface properties of chitosan were acquired from contact angle measurements on a device designed in the lab. Drops of probing liquids, namely water (W), glycerol (Gly), formamide (FA), ethylene glycol (EG), cyclopentane (Cy) were casted on the sample on different surface zones.

\section{Results and discussions}

The behavior of chitosan in a good solvent, like acetic acid, is important for understanding the film properties. Quantitative structure-activity relationship (QSAR) is useful for predicting essential molecular features that depict electrical, optical and biological performance of materials. The parameters that describe the morphological features of the polymer can also be correlated with surface wettability and interfacial forces acting at biointerface. The adhesion/cohesion interactions of chitosan samples with biological fluids and microorganisms must be elucidated for selecting the proper biomedical application for the examined samples.

\subsection{Molecular modeling}

Use of simulations with appropriate software is helpful for clarification of the different behavior of polymers in free space, solvent environment or in interaction with similar/distinct macromolecules. Thermodynamic properties and QSAR parameters are often employed to achieve information on physical properties, which in turn they affect the polymeric material's chemical reactivity and biological activity. Table 1 presents the main results achieved with QSAR for three cases: chitosan in free space, chitosan in acetic acid medium (5 molecules) and chitosan interacting with another chitosan macromolecule (Figure 1). Such computing analyses were done to clarify the variations in the studied biopolymer behavior in different environments.

The total energy (E) of system ranges from $-154067.4 \mathrm{kcal} / \mathrm{mol}$ for the chitosan in vacuum, to $154093.1 \mathrm{kcal} / \mathrm{mol}$ for chitosan in HAc and finally to $-308198.2 \mathrm{kcal} / \mathrm{mol}$ for two macromolecules of chitosan. The HOMO and LUMO difference provides the band gap energy. This parameter is $8.07 \mathrm{eV}$ for chitosan in vacuum and decreases for chitosan/HAc system to $7.76 \mathrm{eV}$, while in the case of chitosan chains interaction this parameter becomes $8.23 \mathrm{eV}$. This result is supported by polarizability $(\alpha)$ values, 
which are ranging in the same trend. The hydration energy $\left(\mathrm{E}_{\mathrm{H}}\right)$ is related to the energy absorbed when the polymer is solubilized in aqueous media. Low $\mathrm{E}_{\mathrm{H}}$ values are linked to a big capacity to dissolve in water and denotes a prevalent hydrophylic character. The binding energy $\left(\mathrm{E}_{\mathrm{B}}\right)$ can be attributed to the system's binding affinity. When chitosan is placed in acetic acid or is interacting with another chitosan the binding energy values are decreasing so its binding affinity is smaller. The partition coefficient $(\log \mathrm{P})$ describes the hydrophilic or hydrophobic nature of the analyzed substance. The simulated chitosan samples present negative values, which illustrate the hydrophilic character of this compound. The surface area grid (S) describes the biological activity of the examined biopolymer. As the charge surface area of a molecule is higher, the ability to destroy pathogens is higher. The charged distribution reflected by electrostatic potential (ESP) is influenced by the surface area. A higher biological activity can be ascribed to a bigger positive charge surface area. The dipole moment $(\mu)$, which describes systems' polarity, increases from 3.25 D for chitosan/ free space to $4.73 \mathrm{D}$ for chitosan interacting with 5 molecules of HAc and to $7.82 \mathrm{D}$ when chitosan is interacting with itself. The systems with higher $\mu$ values present higher attraction with other molecules of biological nature.

Table 1. The values of chitosan physicochemical properties obtained from QSAR: highest occupied molecular orbital (HOMO), lowest unoccupied molecular orbital (LUMO), energy gap $\left(\mathrm{E}_{\mathrm{G}}\right)$, polarizability $(\alpha)$, hydration energy $\left(E_{H}\right)$, binding energy $\left(E_{B}\right)$, partition coefficient $(\log P)$, surface area grid $(\mathrm{S})$, dipole moment $(\mu)$

\begin{tabular}{|c|c|c|c|c|c|c|c|c|}
\hline \multirow[b]{2}{*}{ Sample } & \multicolumn{3}{|c|}{ Parameter } & \multirow[b]{2}{*}{$\begin{array}{c}\mathrm{E}_{\mathrm{H}} \\
(\mathrm{kcal} / \mathrm{mol})\end{array}$} & \multirow[b]{2}{*}{$\begin{array}{c}\mathrm{E}_{\mathrm{B}} \\
(\mathrm{kcal} / \mathrm{mol})\end{array}$} & \multirow[b]{2}{*}{$\log \mathrm{P}$} & \multirow[b]{2}{*}{$\begin{array}{c}\mathrm{S} \\
\left(\AA^{2}\right)\end{array}$} & \multirow[b]{2}{*}{$\begin{array}{c}\mu \\
\text { (Debye) }\end{array}$} \\
\hline & $\begin{array}{c}\text { HOMO } \\
(\mathrm{eV})\end{array}$ & LUMO $(\mathrm{eV})$ & $\begin{array}{c}\alpha \\
\left(\AA^{3}\right)\end{array}$ & & & & & \\
\hline $\begin{array}{c}\text { Chitosan/ free } \\
\text { space }\end{array}$ & -9.3289 & 1.2598 & 43.18 & -29.59 & -6369.9 & -4.81 & 668.4 & 3.25 \\
\hline $\begin{array}{l}\text { Chitosan/ } \\
\text { HAc }\end{array}$ & -9.2225 & 1.4665 & 51.14 & -23.36 & -6395.7 & -3.50 & 775.7 & 4.73 \\
\hline $\begin{array}{l}\text { Chitosan/ } \\
\text { Chitosan }\end{array}$ & -9.3334 & 1.1008 & 86.36 & -34.57 & -12803.3 & -9.62 & 1004.9 & 7.82 \\
\hline
\end{tabular}

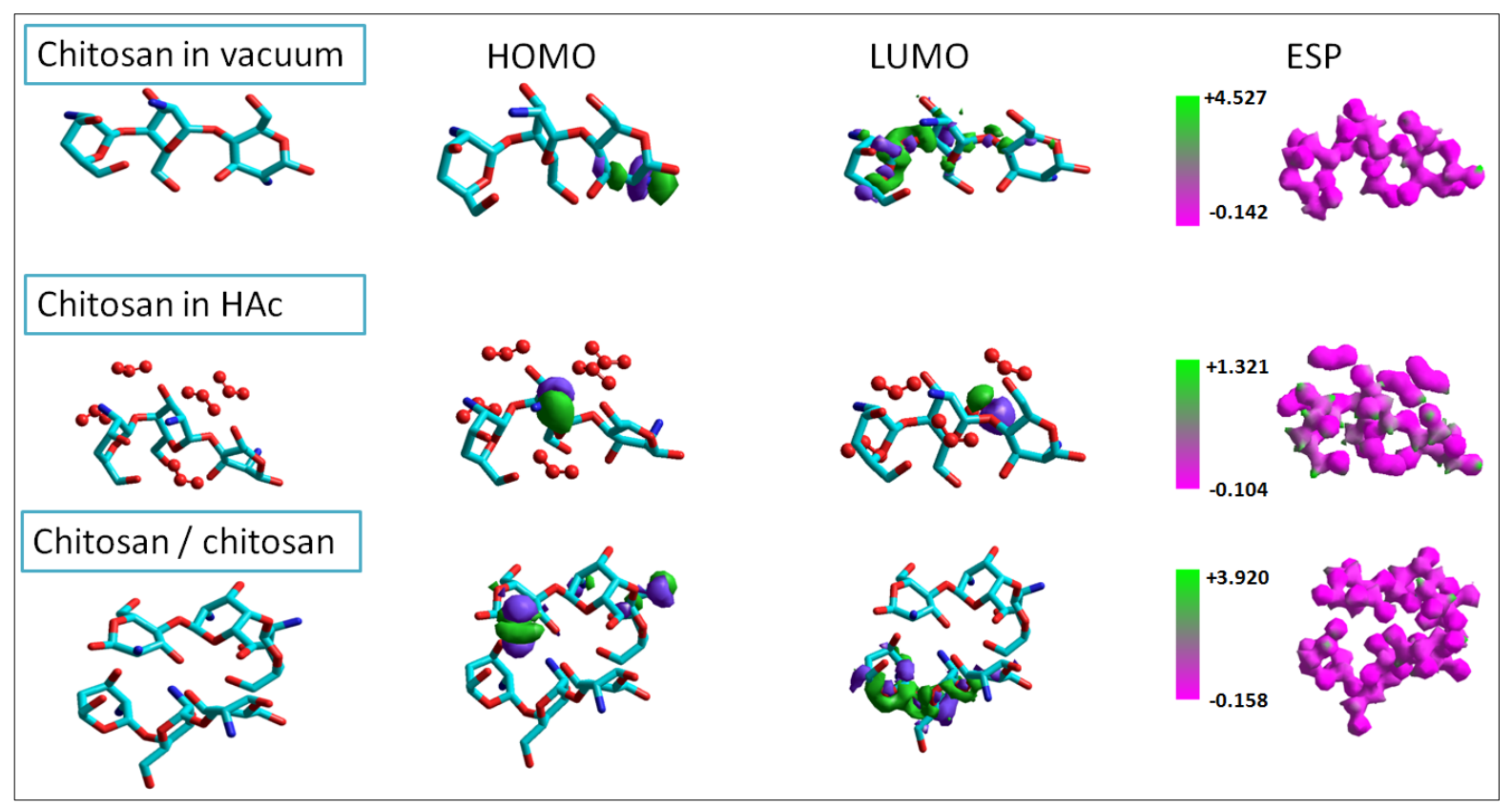

Figure 1. Optimized chitosan structure in different environments, frontier molecular orbitals and electrostatic potential diagram (ESP) 


\subsection{Surface morphology}

The polymer morphological features described by surface topography parameters are of paramount importance in elucidating the manner in which biological media react with chitosan surface. In Figure 2 are presented the bi-dimensional morphological AFM image of chitosan membrane obtained on $20 \times 20$ $\mu \mathrm{m}^{2}$ (a) and corresponding height histogram and Abbott-Firestone curve (surface material ratio curve) (b). The height histogram was used to calculate the amplitude ( $\mathrm{Sq}$ - root mean square roughness) and shape parameters (Sku - kurtosis of height distribution, Ssk - skewness of height distribution). The superposition of the Abbott-Firestone curve on the height histogram helps to indentify three different morphological regions of interest (valley zone, core zone and peak zone), used to calculate the spatial parameters (Stdi - surface texture direction index) and the functional indexes (Sbi - surface bearing index, Sci - core fluid retention index, Svi - valley fluid retention index).

As seen from Figure 2(a), the chitosan membrane revealed a predominantly hill-valley-structured surface of nanoscale topography, typical for this kind of sample [14], indicated by the low root mean square roughness $(\mathrm{Sq}=5.983 \mathrm{~nm})$ and the shape parameters. Thus, the obtained higher positive value of the kurtosis, $\mathrm{Sku}=6.686$, suggest a leptokurtic surface $(\mathrm{Sku}>3)$, with spiky morphology. Also, the positive skewness, $\mathrm{Ssk}=0.388$, reveals profiles with valleys filled in, or occasional high peaks [21]. Spatially, the surface of the chitosan sample do not has a predominant texture direction, in other words is isotropic from the morphology point of view, the texture direction index of the surface, Stdi $=0.750$, being close to 1 . The value of $\mathrm{Sbi}=0.106$ indicate that the surface of the chitosan sample exhibit relatively few high peaks and has low surface bearing properties $(\mathrm{Sbi}<0.608)$. In addition, Svi $=0.104$ suggest relatively few deep valleys, leading to low to moderate valley fluid retention (Svi $\approx 0.11)$. Also, the occasional surface high peaks and deep valleys suggested by Sci $=1.581$, denote a moderate core fluid retention $(\mathrm{Sci} \approx 1.56)$ [21].

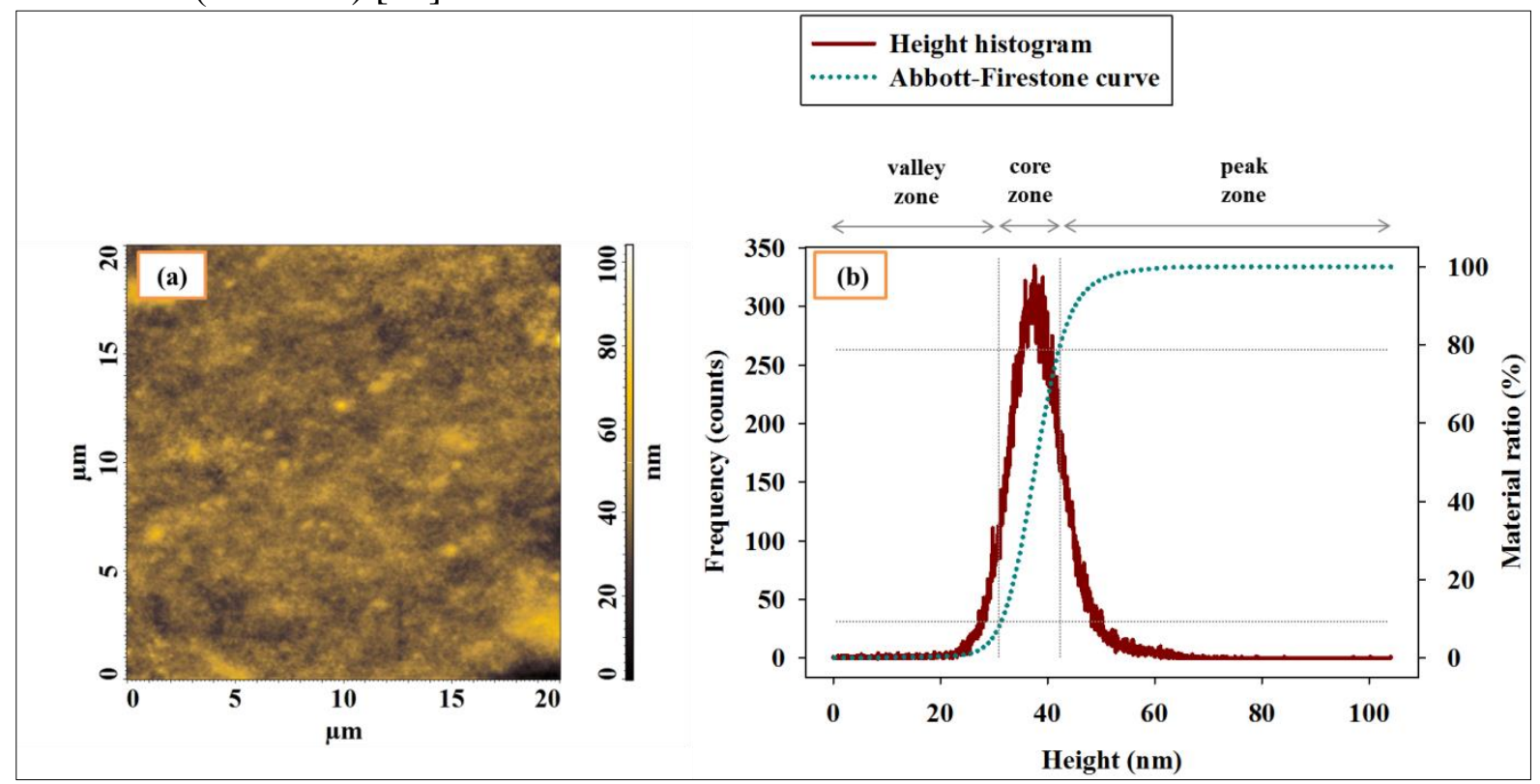

Figure 2. 2D AFM image of chitosan membrane (a) and corresponding height histogram and Abbott-Firestone curve (surface material ratio curve) (b) indicating three different morphological regions of interest (valley zone, core zone and peak zone)

\subsection{Surface wetting features and biointeractions}

Utilization in biomedicine of polymers involves their close contact with biological fluids such as blood. As a result of the wetting ability of these liquids, they form interfaces with the solid polymer layer. In order to evaluate the degree of wetting, the contact angle $(\theta)$ that occurs between the liquid and the polymer surface is experimentally determined. A greater wetting ability is reflected in a lower value of contact angle and surface tension. Owens-Wendt [22] developed an approach which considers surface 
tension of a solid polymer $\left(\gamma_{\mathrm{s}}\right)$ as being composed of a polar and dispersive component, as shown in equation (1):

$$
\gamma_{\mathrm{s}}=\gamma_{\mathrm{s}}^{\mathrm{d}}+\gamma_{\mathrm{s}}^{\mathrm{p}}
$$

where $\gamma_{\mathrm{s}}^{\mathrm{p}}$ is the polar contribution to the surface tension, whereas $\gamma_{\mathrm{s}}^{\mathrm{d}}$ is the dispersive one.

By introducing the contact angle data in the equation (2) proposed by Owens-Wendt [22], the surface tension parameters can be determined:

$$
\frac{1+\cos \theta}{2} \cdot \frac{\gamma_{l}}{\sqrt{\gamma_{l}^{d}}}=\sqrt{\gamma_{s}^{p}} \cdot \sqrt{\frac{\gamma_{l}^{p}}{\gamma_{l}^{d}}}+\sqrt{\gamma_{s}^{d}}
$$

where the letters "s" and "l" are illustrating the solid and liquid phase.

Drops of several probing liquid of known surface tension [23] were placed on chitosan film sample, leading to the following results: $\theta_{\mathrm{W}}=85^{\circ}, \theta_{\mathrm{FA}}=61^{\circ}, \theta_{\mathrm{EG}}=53^{\circ}, \theta_{\mathrm{Gly}}=70^{\circ}, \theta_{\mathrm{Cy}}=19^{\circ}$. When plotting $\frac{1+\cos \theta}{2} \cdot\left(\gamma_{1} / \sqrt{\gamma_{1}^{\mathrm{d}}}\right)$ against $\sqrt{\gamma_{1}^{\mathrm{p}} / \gamma_{1}^{\mathrm{d}}}$ for the examined biopolymer, it is possible to obtain the pursued surface tension parameters by extracting the data from the slope and intercept of the straight line presented in Figure 3.

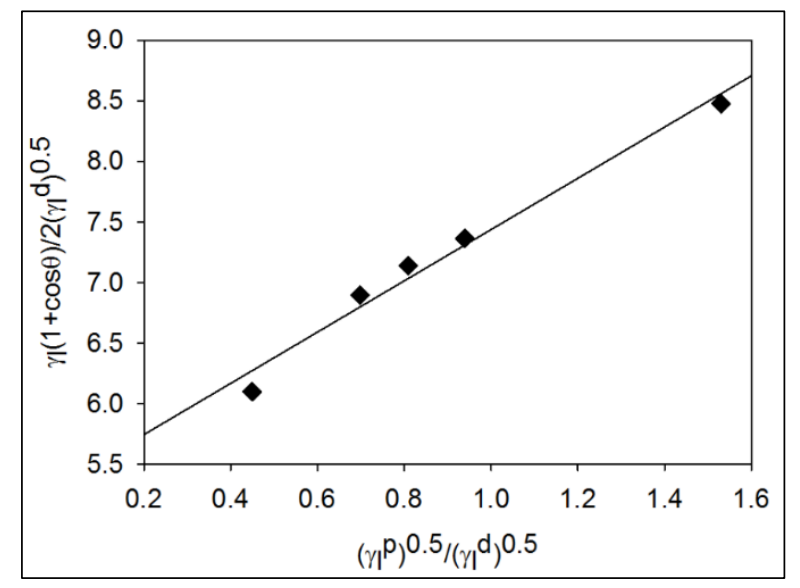

Figure 3. The Owens/Wendt graph resulted from contact angle measurements of probing liquids on chitosan samples

For the prepared chitosan film, the values of $\gamma_{\mathrm{s}}^{\mathrm{p}}$ and $\gamma_{\mathrm{s}}^{\mathrm{d}}$ were $4.45 \mathrm{mN} / \mathrm{m}$ and $28.30 \mathrm{mN} / \mathrm{m}$, respectively. The result is in good acordance with other reports on chitosan surface energy [10-16]. The slight differences between our results and some of the published values of other authors arise from the quality of chitin precursor, molecular weight and its further chemical processing (degree of deacetylation). Regardless these aspects, our data and literature [1-16] reveal that chitosan films present predominant dispersive surface properties. The magnitude of the polar and dispersive contributions to surface tension determines the interaction of the polymer sample with biological fluids or microorganisms. The prevalent forces acting at chitosan biointerface can be quantified through the work of spreading (Ws) defined by equation (3):

$$
\mathrm{Ws}=\mathrm{Wa}-\mathrm{Wc}=2 \cdot \sqrt{\gamma_{\mathrm{s}}^{\mathrm{d}} \gamma_{\mathrm{b}}^{\mathrm{d}}}+2 \cdot \sqrt{\gamma_{\mathrm{s}}^{\mathrm{p}} \gamma_{\mathrm{b}}^{\mathrm{p}}}-2 \gamma_{\mathrm{b}}
$$

where Wa is the work of adhesion, Wc is work of cohesion, and the index "b" is for the biological medium considered to interact with the chitosan sample.

For biomedical applications that impose direct contact of the polymer material with blood, it is very 
important to determine the wetting or dewetting tendency of the biological liquid at the interface. To elucidate the biointeractions it is convenient to determine the spreading work of the most relevant blood constituents. The obtained results are depicted in Figure 4(a) which denotes negative values of Ws parameter for blood and its components. In other words, this is equivalent with a prevalent cohesion of blood fluid and of its cells and proteins with chitosan surface. In this case, the sanguine proteins (albumin, fibrinogen, immunoglobulin IgG) are not adsorbed by superficial layers of chitosan film. This is beneficial for avoiding undesired clotting processes. Moreover, in order to attain a good hemocompatibility the blood cells must not adhere to the sample surface to keep their initial morphology and functionality. In contact with chitosan, erythrocytes and thrombocytes are interacting via cohesive forces. Thus, the transport of oxygen to the tissues is not affected by the polymer presence, but also no activation of platelets occurs so clotting is not triggered. This is also supported by morphology scans that indicate a lack of predominant texture direction, few high peaks and low to moderate valley fluid retention on the chitosan surface. These topography characteristics of chitosan reveal that such morphology would not perturb blood flow in contact with the sample surface. These aspects are favorable for using chitosan in fabrication of materials for blood-related applications [24].

Other biomedical applications require biopolymers that inhibit the microorganism proliferation through their surface characteristics. Such polymer materials with bacteriostatic properties are useful for manufacturing of medical instrumentation such as syringes, housings, tubing, filters, pipettes and connectors. For these practical purposes, it is imperative to have predominant cohesive force at the polymer interface with microorganisms. Several categories of microbial strains were considered in this investigation, namely: actinomyces, candida, capnocytophaga, escherichia, lactobacilli, prevotella, staphylococci, serratia, and streptococci. The spreading tendency of each of these microorganisms on chitosan sample is presented in Figure 4(b). It must be remarked that for all microbial strains the cohesion forces overcome the adhesion ones leading to negative Ws values. The surface features of chitosan impede the growth of microorganisms, which is in agreement with morphology data regarding low surface bearing properties. Literature [25-30] discusses the spectrum of antimicrobial activity of chitosan against Gram-positive and Gram-negative bacteria, fungi and viruses. The reports are focused on the following microbial strains: Stenotrophomonas maltophilia, Enterobacter cloacae, Actinobacillus actinomycetemcomitans, Streptococcus mutans, Porphyromonas gingivalis, Bacillus cereus, S. aureus, E. coli, Bacillus subtilis, Bacillus cereus, Pseudomonas aeruginosa, Salmonella typhimurium,Vibrio cholerae, Shigella dysenteriae, Prevotella melaninogenica, Bacteroides fragilis, Staphylococcus simulans [25-30]. Based on these publications, it was concluded that chitosan's activity is mostly growthinhibitory and it is possible for resistant subpopulations to emerge if they succeed to adapt to chitosan stress [31]. In addition, after removing chitosan from the bacterial culture, it was found that some bacteria could rapidly grow back. This can be explained by the irreversible binding of the biopolymer to microbial cells or medium particles, which makes it inactive against the rest of the unbound microorganisms [32].

The cationic antibacterial agents, like chitosan, are believed to display several modes of action. One of them relies on the interaction and destruction of the cell envelope. So, the positively charged - NH3+ groups of glucosamine present in chitosan structure represent an essential factor in the interaction with negatively charged surface parts of the bacteria and fungi and consequently could produce cell surface disruption and leakage of intracellular substances, which finally cancels the bacterial activities [33]. Another mode of action is thought to rely on chitosan interaction with microbial DNA that in turn inhibits the microbial RNA and protein production as a result of biopolymer infiltration into the nuclei of the microorganisms [34]. Other mechanisms of action are considered to arise from the chelating properties of chitosan which enables binding of metals and hinder the production of toxins and microbial proliferation [35]. Also, the antibacterial activity of chitosan could reside in its ability to deposit on the outer shell of the bacteria thus inhibiting mass transfer and suppressing the metabolic activity of the microorganism [36]. Based on our study, the bacteriostatic ability of chitosan was assessed for other unreported microbial strains. This was also remarked for chitosan's precursor (i.e. chitin), which was 
proved to display bacteriostatic behavior [37]. The strongest cohesion forces are acting at the interface of chitosan with C. gingivalis, P. intermedia, and S. marcescens. These bacteria are responsible for infections in oropharyngeal tract, periodontal tissue, and hospital-acquired infections, like those related to respiratory and urinary tracts. Medium negative Ws values were noticed for L. acidophilus - found in gastrointestinal tract and mouth and S. epidermidis - encountered in skin flora. These two bacteria are naturally produced by human organism, and they are not usually pathogenic. However, patients with damaged immune systems are at risk of to be infected with these microorganisms. E. coli, A. naeslundii, C. albicans and S. oralis are causing oral and gut infections, but they do not adhere on chitosan surface even if the Ws values in these cases are smaller they are still negative. For all considered biological media/chitosan interfaces, no adhesion was attained, so the investigated biopolymer presents adequate properties for biomedical applications.

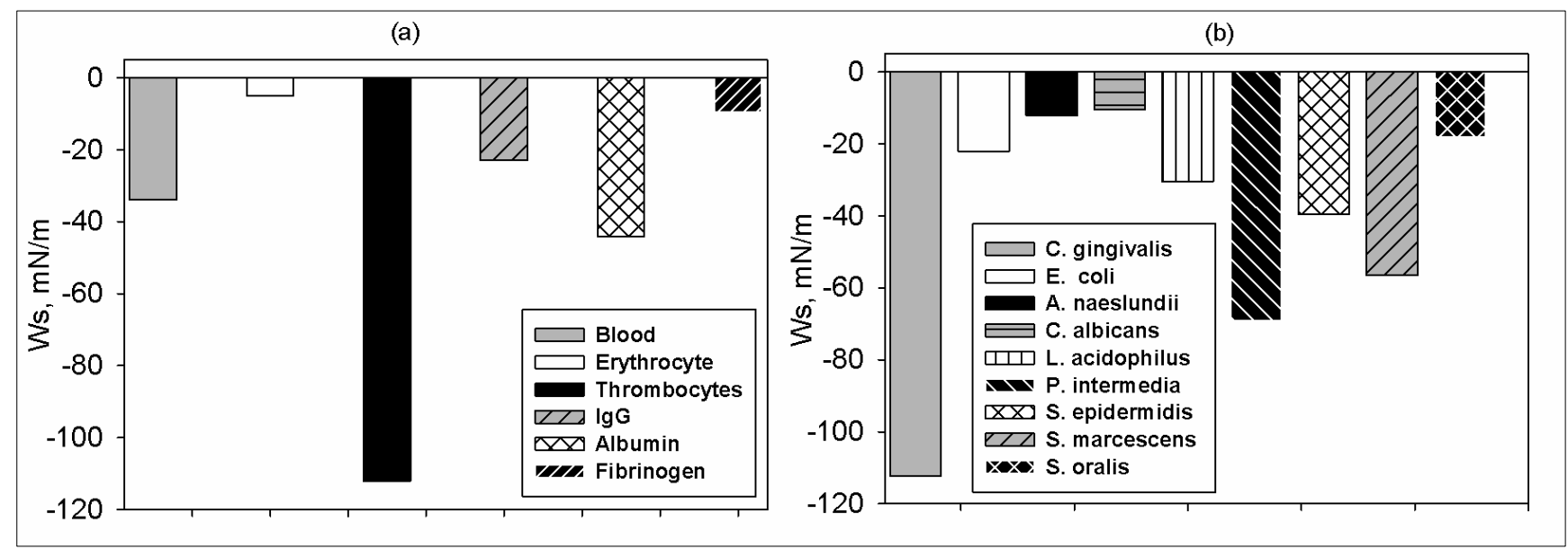

Figure 4. The spreading work of of blood and its constituents (a) and of microorganisms (b) on examined chitosan sample

\section{Conclusions}

The physicochemical properties of chitosan are affected by the simulation environment. The values of surface area grid and LogP show that the hydrophilic character and biological activity are higher for chitosan interacting with itself comparatively with chitosan/HAc system.

The morphology of the chitosan membrane unveil a predominantly hill-valley-structured surface of nanoscale topography, with no predominant texture direction, low surface bearing properties, low to moderate valley fluid retention.

The contact angle results allow estimation of the spreading work of blood and microorganisms on chitosan film surface. Blood proteins and cells are interacting through cohesion forces with investigated biopolymer sample. The same behavior was remarked when for citosan/microorganism interface. No adhesion of bacterial strains resulted from analysis of spreading work data.

Considering the obtained results, one may conclude that chitosan sample is suitable for bloodcontacting devices, but also is a good candidate for preparation of medical instrumentation with antibacterial features.

\section{References}

1. POPA, E.E., RAPA, M., CORNEA, C.P., POPA, V.I., MITELUT, A.C., POPA, O., CRISTEA, M.G., POPA, M.E., PHB/cellulose fibres composites colonization and biodegradation behavior, Mater. Plast., 55(1), 2018, 48-53

2. DIMONIE, D., DAMIAN, C., TRUSCA, R., RAPA, MARIA., Some aspects conditioning the achieving of filaments for 3D printing from physical modified corn starch, Mater. Plast., 56(2), 2019, 351-359 
3. RAMYA, R., VENKATESAN, J., KIM, S.E., SUDHA, P.N., Biomedical applications of chitosan: an overview, J. Biomater. Tissue Eng., 2, 2012, p. 100-111.

4. ZHAO, D., YU, S., SUN, B., GAO, S., GUO, S., ZHAO, K., Biomedical applications of chitosan and its derivative nanoparticles, Polymers, 10, 2018, p. 462-478

5. YOUNES, I., RINAUDO, M., Chitin and chitosan preparation from marine sources. Structure, properties and applications, Mar. Drugs., 13, no. 3, 2015, p. 1133-1174

6. LEERTOUWER, H.L., WILTS, B.D., STAVENGA, D.G., Refractive index and dispersion of butterfly chitin and bird keratin measured by polarizing interference microscopy, Opt. Express, 19, no. 24, 2011, p. 24061-24066

7. CAMPOS-FERNÁNDEZ, C., AZOFEIFA, D.E., HERNÁNDEZ-JIMÉNEZ, M., RUIZ-RUIZ, A., VARGAS, W.E., Visible light reflection spectra from cuticle layered materials, Opt. Mater. Exp., 1, no. 1, 2011, p. 85-100

8. GALED, G., MIRALLES, B., INÉS PAÑOS, I., SANTIAGO, A., HERAS, Á., N-Deacetylation and depolymerization reactions of chitin/chitosan: Influence of the source of chitin, Carbohydr. Polym., 62, no. 4, 2005, p. 316-320.

9. VUNAIN, E., MISHRA, A.K., MAMBA, B.B., Fundamentals of chitosan for biomedical applications, Chitosan Based Biomaterials, Volume 1, Woodhead Publishing, Eds.: Jennings, J.A., Bumgardner, J.D., UK, 2017, p. 3-30

10. WONG, D.W.S., GASTINEAU, F.A., GREGORSKI, K.S., TILliN, S.J., PAVLATH, A. E., Chitosan-lipid films: microstructure and surface energy, J. Agric. Food Chem. 40, 1992, p. 540-544

11. RILLOSI, M., BUCKTON, G., Modelling mucoadhesion by use of surface energy terms obtained from the Lewis Acid-Lewis Base Approach. II. Studies on Anionic, Cationic, and Unionisable Polymers, Pharm. Res., 12, no. 5, 1995, p. 669-675

12. YAMATOTO, H., NISHIDA, A., OHKAWA, K. Wettability and adhesion of marine and related adhesive proteins, Colloids Surf. A, 149, 1999, p. 553-559

13. SIONKOWSKA, A., KACZMAREK, H., WISNIEWSKI, M., SKOPINSKA, J., LAZARE, S., TOKAREV, V. The influence of UV irradiation on the surface of chitosan films, Surf. Sci., 600, 2006, p. 3775-3779

14.AMARAL, I.F., GRANJA, P.L., MELO, L.V., SARAMAGO, B., BARBOSA, M. A., Functionalization of chitosan membranes through phosphorylation: atomic force microscopy, wettability, and cytotoxicity studies, J. Appl. Polym. Sci., 102, no. 1, 2006, p. 276-284

15. CHRZANOWSKA, E., GIERSZEWSKA, M., KUJAWA, J., RASZKOWSKA-KACZOR, A., KUJAWSKI, W., Development and characterization of polyamide-supported chitosan nanocomposite membranes for hydrophilic pervaporation, Polymers, 10, 2018, p. 868-888

16. CUNHA, A.G., FERNANDES, S.C.M., FREIRE, C.S.R., SILVESTRE, A.J.D., NETO, C.P., GANDINI, A., What Is the Real Value of Chitosan's Surface Energy? Biomacromolecules, 9, no. 2, 2008, 610-614

17. ENESCU, D., HAMCIUC, V., ARDELEANU, R., CRISTEA, M., IOANID, A., HARABAGIU, V., SIMIONESCU, B.C., Polydimethylsiloxane modified chitosan. Part III: Preparation and characterization of hybrid membranes, Carbohydr. Polym., 76, no. 2, 2009, p. 268-278

18. ALDANA, A.A., BARRIOS, B., STRUMIA, M., CORREA, S., MARTINELLI, M., Dendronization of chitosan films: Surface characterization and biological activity, React. Funct. Polym., 100, 2016, p. $18-25$

19. AKTER, N., KHAN, R.A., TUHIN, M.O., EMDADU HAQUE, M., NURNABI, M., PARVIN, F., ISLAM, R., Thermomechanical, barrier, and morphological properties of chitosan-reinforced starchbased biodegradable composite films, J. Thermoplast. Compos. Mater., 27, no. 7, 2014, p. 933-948 20. PRAXEDES, A.P.P., WEBLER, G.D., SOUZA, S.T., RIBEIRO, A.S., FONSECA, E.J.S., de OLIVEIRA, I.N., Non-monotonic wetting behavior of chitosan films induced bysilver nanoparticles, Appl. Surf. Sci., 370, 2016, p. 25-31 
21. STOICA, I., BARZIC, A.I., HULUBEI, C., TIMPU, D., Statistical Analysis on Morphology Development of Some Semialicyclic Polyimides Using Atomic Force Microscopy, Microsc. Res. Tech.,

76, 2013, p. 503-513

22. OWENS, D., WENDT, R., Estimation of the surface free energy of polymers, J. Appl. Polym. Sci., 13, 1969, p.1741-1747

23. RANKL, M., LAIB, R., SEEGER, S., Surface tension properties of surface-coatings for application in biodiagnostics determined by contact angle measurements, Colloids Surf. B, 30, 2003, p. 177-186

24. BALAN, V., VERESTIUC, L., Strategies to improve chitosan hemocompatibility: A review, Eur. Polym. J., 53, 2014, p. 171-188

25. CHIRKOV, S.N., The antiviral activity of chitosan, Appl. Biochem. Microbiol., 38, 2002, p.1-8 (In Russian)

26. RAAFAT, D., SAHL, S.G., Chitosan and its antimicrobial potential - a critical literature survey, Microb. Biotechnol., 2, no. 2, 2009, p. 186-201

27. KONG, M., CHEN, X.G., XING, K., PARK, H.J., Antimicrobial properties of chitosan and mode of action: A state of the art review, Int. J. Food Microbiol., 144, no. 1, 2010, p. 51-63

28. VILAR Jr., J.C., RIBEAUX, D.R., da SILVA, C.A.A., De CAMPOS-TAKAKI, G.M., Physicochemical and Antibacterial Properties of Chitosan Extracted from Waste Shrimp Shells, Int. J. Microbiol., 2016, 2016, p. 1-7

29. HAFSA, J., SMACH, M.A., CHARFEDDINE, B., LIMEM, K., MAJDOUB, H., ROUATBI, S., Antioxidant and antimicrobial proprieties of chitin and chitosan extracted from Parapenaeus Longirostris shrimp shell waste, Ann Pharm. Fr., 74, no. 1, 2016, p. 27-33

30. BENHABILES, M.S., SALAH, R., LOUNICI, H., DROUICHE, N., GOOSEN, M.F.A., MAMERI, N., Antibacterial activity of chitin, chitosan and its oligomers prepared from shrimp shell waste, Food Hydrocolloid, 29, 2012, p. 48-56

31. RAAFAT, D., VON BARGEN, K., HAAS, A., SAHL H.G., Insights into the mode of action of chitosan as an antibacterial compound, Appl. Environ. Microbiol., 74, 2008, p. 3764-3773

32. RHOADES, J., ROLLER, S., Antimicrobial actions of degraded and native chitosan against spoilage organisms in laboratory media and foods, Appl. Environ. Microbiol., 66, 2000, p. 80-86

33. JE, J.Y., KIM, S.K., Chitosan derivatives killed bacteria by disrupting the outer and inner membrane. J Agric Food Chem., 54, 2006, p. 6629-6633

34. GOY, R.C., de BRITTO, D., ASSIS, O.B.G., A Review of the Antimicrobial Activity of Chitosan, Polímeros: Ciência e Tecnologia, 19, no. 3, 2009, p. 241-247

35. CHUNG, Y.C., WANG, H.L., CHEN, Y.M., LI, S.L., Effect of abiotic factors on the antibacterial activity of chitosan against waterborne pathogens, Bioresour Technol., 88, 2003, p. 179-184

36.KUMAR, A.B.V., VARADARAJ, M.C., GOWDA, L.R., THARANATHAN, R.N., Characterization of chito-oligosaccharides prepared by chitosanolysis with the aid of papain and pronase, and their bactericidal action against Bacillus cereus and Escherichia coli, Biochem. J., 391, 2005, p. 167-175 37. BARZIC, A.I., ALBU, R.M., Optical properties and biointerface interactions of chitin, Polym. Bull., 2020, POBU-D-20-00148R1

Manuscript received: 26.02.2020 